\title{
Contrasting effects of circulating nitric oxide and nitrergic transmission on exocrine pancreatic secretion in rats
}

\author{
E Vaquero, X Molero, V Puig-Diví, J-R Malagelada
}

\begin{abstract}
Background-Nitric oxide (NO) blockade by L-nitroarginine methyl ester (L-NAME) inhibits pancreatic secretion in vivo and aggravates caerulein induced pancreatitis. Nitric oxide synthase (NOS) is present in pancreatic islets, endothelium, and nerve fibres. L-NAME blocks all known NOS isoforms.
\end{abstract}

Aim-To investigate the source of NO blocked by L-NAME that inhibits amylase secretion.

Methods-Amylase output was measured in rats in response to caerulein (0.1-50 $\mu \mathrm{g} / \mathrm{kg}$ ) alone or with indazole. Baseline secretion and the response to supramaximal caerulein were also examined after administration of indazole, L-NAME, haemoglobin, or aminoguanidine under continuous blood pressure measurement. In separate experiments, pancreatic secretion was measured after blockade of afferent nerve fibres by either systemic or local capsaicin. The effect of neural NOS inhibition on caerulein induced pancreatitis was also investigated.

Results-L-NAME, haemoglobin, and supramaximal caerulein $(10 \mu \mathrm{g} / \mathrm{kg})$ increased blood pressure, whereas indazole and suboptimal caerulein $(0.1 \mu \mathrm{g} / \mathrm{kg})$ did not. Indazole and capsaicin decreased basal amylase output. L-NAME and haemoglobin reduced basal amylase output to a lesser extent and potentiated the inhibitory response to supramaximal caerulein. In contrast, full neural NOS inhibition by L-NAME partially reversed the expected caerulein induced suppression of amylase output. This effect was reproduced by indazole and capsaicin. Indazole did not alter responses to either optimal $(0.25 \mu \mathrm{g} / \mathrm{kg})$ or suboptimal $(0.1$ $\mu \mathrm{g} / \mathrm{kg}$ ) caerulein, nor, in contrast with L-NAME, aggravate the outcome of caerulein induced pancreatitis.

Conclusions-Reduction of circulating NO availability, probably of endothelial origin, is responsible for the decrease in amylase secretion observed in the early response to L-NAME. Nitrergic neurotransmission plays an important role in the control of pancreatic secretion and may induce opposite effects to endothelial NOS activity.

(Gut 1998;43:684-691)

Keywords: nitric oxide; pancreatic secretion; pancreatitis; indazole; haemoglobin
Inhibition of endogenous nitric oxide (NO) synthesis by L-nitroarginine methyl ester (LNAME) decreases basal and stimulated pancreatic secretion in vivo. This process has been shown in several species including the rat, pig, cat, and $\operatorname{dog},{ }^{1-4}$ but its mechanism of action is poorly understood.

In the normal pancreas, nitric oxide synthase (NOS) is present in the endothelium, nerve fibres, and islets of Langerhans..$^{5-7}$ Immunostaining techniques do not show the presence of NOS in exocrine cells, ${ }^{7}$ whereas functional studies indicate that NOS activity is present. ${ }^{18}$ In fact, NOS may be involved in the control of agonist stimulated calcium influx. ${ }^{8}$ However, in dispersed pancreatic acini, blockade of NO production by L-NAME has not proven to be detrimental to amylase secretion, ${ }^{1}$ an observation that is consistent with the lack of effect of intracellular modifications of cGMP concentration on amylase release. ${ }^{9}$

L-NAME (and most other structurally related compounds) exerts an inhibitory effect over all NOS isoforms, being effective on a wide variety of cell types. Thus L-NAME elicits a powerful and sustained vasopressor response, increasing mean arterial pressure $(\mathrm{MAP})^{10}$ (as the result of endothelial NOS blockade), inducing anti-nociception by inhibiting neural NOS (nNOS) preventing NO mediated neurotransmission (nitrergic transmission), ${ }^{11}$ and disrupting the regulation of islet hormone secretion ${ }^{6}{ }^{12}$ by interfering with NOS activity in the islets of Langerhans.

We have previously shown that L-NAME inhibits in vivo pancreatic secretion stimulated by optimal and supramaximal doses of caerulein when both drugs are infused simultaneously. ${ }^{1}$ However, L- $N^{\mathrm{G}}$-nitroarginine (the compound that results from hydrolysis of L-NAME and often regarded as equivalent to L-NAME) ${ }^{13}$ shows progressive and irreversible inhibition of nNOS. ${ }^{14} 15$ We hypothesised that selective NOS inhibition may reveal the specific role of various NOS sites in pancreatic exocrine secretion. The aim of the present study was to establish the source of NO that, when blocked, is associated with decreased pancreatic secretion in vivo. A pharmacological strategy was employed: the pattern of amylase secretion was examined in the anaesthetised rat in response to selective compounds that interact with the normal physiology (trafficking) of NO.

Indazole inhibits nNOS without interfering with endothelial NOS activity in vivo. ${ }^{16}$ Thus MAP is not modified by systemic indazole. In
Accepted for publication 29 April 1998 
Table 1 Summary of study groups, route of drug administration, dose and schedule of caerulein challenges

\begin{tabular}{lll}
\hline Experimental group & Dose, route of administration & Time before caerulein stimulation \\
\hline Control (vehicle) & i.v./i.p. & - \\
L-NAME & $30 \mathrm{mg} / \mathrm{kg}$, i.v. & $2 \mathrm{~min}$ \\
L-NAME 25 & $30 \mathrm{mg} / \mathrm{kg}$, i.v. & $25 \mathrm{~min}$ \\
Indazole & $50+50 \mathrm{mg} / \mathrm{kg}$, i.p. & 50 and $2 \mathrm{~min}$ \\
Indazole 100 & $100 \mathrm{mg} / \mathrm{kg}$, i.p. & 2 min \\
Systemic capsaicin & $150 \mathrm{mg} / \mathrm{kg}$, s.c. & 5 days \\
Local capsaicin & $0.1 \%, \mathrm{perivagal}+1 \%$ intraduodenal & 5 days \\
Caerulein alone & $0.1-50 \mu \mathrm{gg} / \mathrm{kg}$, i.v. & - \\
Haemoglobin & $500+500 \mathrm{mg} / \mathrm{kg}$, i.v. & 2 min \\
Aminoguanidine & $40 \mathrm{mg} / \mathrm{kg}$, i.v. & 60 and $2 \mathrm{~min}$
\end{tabular}

i.v., intravenous; i.p., intraperitoneal; s.c., subcutaneous.

our study, indazole was used to investigate the effects of selective inhibition of nNOS on pancreatic secretion. ${ }^{16-20}$ Capsaicin is a sensory neurotoxin with highly selective effects on a subset of primary afferent sensory neurons, including nociceptive neurons. Systemic administration or high concentration local application produces anti-nociceptive effects. ${ }^{21-23}$ $\mathrm{NO}$ has been shown to be formed and released in capsaicin sensitive afferent fibres. ${ }^{24}{ }^{25}$ Thus to demonstrate the contribution of nitrergic fibres to the control of pancreatic secretion without interference from inhibition of other NO sources, amylase output was measured in response to caerulein after either inhibition of neural transmission of $\mathrm{NO}$ by indazole or afferent sensorial nerve fibre ablation by capsaicin.

Since a selective inhibitor for endothelial NOS is not currently available, intravenous (i.v.) infusion of haemoglobin was used to decrease plasmatic free NO acutely. Reduced haemoglobin avidly binds free $\mathrm{NO}^{26}{ }^{27}$ and it has been used as an NO scavenger to investigate the effects of acute NO removal from blood. ${ }^{28}$ It appears to have little or no effect on nitrergic transmission ${ }^{26}$ in vivo. The effects of inhibition of the inducible isoform of NOS (non-neural, non-endothelial) by aminoguanidine on pancreatic secretion were also examined.

In a previous study ${ }^{1}$ we have shown that L-NAME, besides potentiating the inhibition of pancreatic secretion elicited by supramaximal doses of caerulein, also aggravates some of the parameters commonly used to assess pancreatic injury in caerulein induced pancreatitis. In addition, L-NAME has also been shown to increase tissue levels of trypsinogen activation peptide, an index of the amount of tissue necrosis. ${ }^{29}$ To determine whether specific inhibition of nNOS may play a role in the development of acute pancreatitis in this model, the effects of indazole on three distinct features of acute pancreatic injury (amylasaemia, tissue oedema, and polymorphonuclear infiltration) were evaluated.

\section{Materials and Methods}

MATERIALS

Ketamine was from Parke-Davis SL (EL Prat de Llobregat, Spain). Caerulein, L-NAME, bovine haemoglobin, bovine serum albumin, aminoguanidine, capsaicin, and sodium dithionite were from Sigma Chemical Co
(Alcobendas, Spain). Indazole was purchased from Boehringer (Mannheim, Germany).

ANIMAL PREPARATION

Experiments were conducted on a total of 214 male Sprague-Dawley rats weighing between 220 and 320 g. After an overnight fast, rats were anaesthetised with ketamine $(100 \mathrm{mg} / \mathrm{kg}$ body weight intraperitoneally (i.p.)), with subsequent intramuscular (i.m.) doses used as necessary to maintain anaesthesia. A jugular vein was cannulated (polyethylene catheter PE-10; Clay Adams, Parsippany, New Jersey, USA) for drug administration and continuous saline perfusion at $3 \mathrm{ml} / \mathrm{h}$ by means of a syringe pump. A heparinised $(10 \mathrm{U} / \mathrm{ml})$ catheter (PE-50) was placed into the carotid artery to monitor blood pressure and to facilitate blood sampling. A pressure transducer was connected to the carotid catheter for continuous recording of MAP in the anaesthetised resting state and in response to administration of drugs.

Animals were then laparotomised and the biliopancreatic duct was cannulated through its duodenal opening (PE-50). The abdominal wound was covered with a saline moisturised gauze, and body temperature was maintained with a heating lamp.

\section{EXPERIMENTAL PROTOCOLS}

Measurement of pancreatic secretion

Pancreatic secretion was measured as previously described. ${ }^{1}$ Briefly, after completion of surgical procedures, biliopancreatic secretion was allowed to drain freely for 30 minutes before initiation of the experiments (stabilisation period). Then secretion was collected in tared vessels in separate 10 minute fractions for 60 minutes and volumes estimated by weight. Amylase output was calculated by determining amylase concentration in the collected fractions. The mean amylase output obtained from two consecutive 10 minute fractions after the stabilisation period was taken as the initial "basal" secretion. Separate experiments were performed to calculate the secretory response to vehicle, NOS inhibitors, haemoglobin, or caerulein at the indicated doses, administered as an i.v. bolus injection at the end of the 20 minutes of basal collection (time 0 ). Table 1 summarises the various groups entering the study.

Basal secretions tend to fluctuate spontaneously over time, ${ }^{30}$ and bursts of secretion occur in a cyclic pattern every two hours or less. ${ }^{31}$ Accordingly, when unstimulated basal secretion was analysed, data on amylase output were standardised by expressing results as a percentage of the variation from initial basal output.

NOS blockade by $L-N A M E$

The effects of L-NAME were investigated after i.v. administration of $30 \mathrm{mg} / \mathrm{kg}$ at time 0 . Neural NOS inhibition by i.p. L-NAME is best manifested starting 15 minutes after its administration, ${ }^{11}$ at a time when there are no further increments in arterial blood pressure. Thus, to investigate most effectively the effect of $\mathrm{nNOS}$ inhibition by L-NAME on pancreatic 
secretion, amylase output was measured in response to supramaximal caerulein $(10 \mu \mathrm{g} /$ $\mathrm{kg}$ ), infused either 2 or 25 minutes after L-NAME $(30 \mathrm{mg} / \mathrm{kg})$.

Specific inhibition of neural NOS

Indazole $(100 \mathrm{mg} / \mathrm{kg}$, i.p.) was dissolved in one part of ethanol and five parts of peanut oil $(\mathrm{v} / \mathrm{v})$ to a maximal volume of $1 \mathrm{ml}$. Pancreatic secretion was measured as described above. Indazole or vehicle was administered i.p. at the end of the initial two 10 minute basal periods (time $0)$.

Since the effects of L-NAME on pancreatic secretion were analysed both at 2 and 25 minutes from its administration, two protocols were conducted to examine the effects of indazole on caerulein stimulated pancreatic secretion. Indazole (or vehicle) was given in two equally divided doses $(100 \mathrm{mg} / \mathrm{kg}$ total, i.p.) 50 and 5 minutes before juice collection. Pancreatic secretion was then measured as described above in independent experiments in response to $0.1,0.25,1,10$, or $50 \mu \mathrm{g} / \mathrm{kg}$ caerulein (bolus i.v.). In a second set of experiments, indazole $(100 \mathrm{mg} / \mathrm{kg})$ or vehicle was administered 2 minutes before $10 \mu \mathrm{g} / \mathrm{kg}$ caerulein.

\section{Ablation of sensorial afferent nerve fibres by capsaicin}

To investigate the effects of functional destruction of afferent nerve fibres on pancreatic secretory response to supramaximal caerulein, capsaicin was administered according to two different protocols (systemic or local administration) five days before measurement of pancreatic secretion in response to i.v. caerulein $(10 \mu \mathrm{g} / \mathrm{kg})$.

\section{Systemic capsaicin administration}

Capsaicin as a $1 \%(\mathrm{w} / \mathrm{v})$ solution was dissolved in ethanol/Tween $80 /$ saline (10:10:80, by vol). Under light ether anaesthesia, rats were injected subcutaneously (s.c.) with capsaicin in three divided doses on three consecutive days for a total dose of $150 \mathrm{mg} / \mathrm{kg}$ in a regimen shown to induce functional ablation of primary afferent sensitive fibres. ${ }^{32}$ Rats were pretreated with terbutaline $(0.1 \mathrm{mg} / \mathrm{kg}, \mathrm{i} . \mathrm{m}$.) and aminophylline $(10 \mathrm{mg} / \mathrm{kg}$, i.m.) before capsaicin injections to prevent acute respiratory distress. On the day before the experiments, defunctionalisation of afferent neurons was ascertained by evaluating the reduction of wiping movements in response to intraocular instillation of a $0.1 \%$ solution of capsaicin. A reduction of more than $80 \%$ compared with control rats was considered an adequate sensitive defunctionalisation. ${ }^{33}$

\section{Local capsaicin administration}

Rats were anaesthetised with ketamine. After a midline incision, both subdiaphragmatic vagal trunks were exposed and surrounded with a small piece of gauze soaked with $100 \mu 10.1 \%$ capsaicin for 30 minutes. In addition, a gauze soaked with $200 \mu \mathrm{l} \quad 0.5 \%$ capsaicin was advanced to the duodenum from the stomach through an antral incision and applied to the duodenal mucosa for 30 minutes. When treat- ment was completed, all of the gauzes were removed and the incisions sutured. Animals were allowed to recover from surgery and experiments conducted five days later.

Removal of circulating $\mathrm{NO}$

Reduced haemoglobin was prepared as previously described ${ }^{34}$ by adding to a $1 \mathrm{mmol} / 1$ solution of haemoglobin in distilled water, a 10 -fold molar excess of the reducing agent, sodium dithionite. The sodium dithionite was then removed by dialysis against $100 \mathrm{vol}$ of saline for two hours at $4^{\circ} \mathrm{C}$. This solution was warmed to $37^{\circ} \mathrm{C}$ before infusion.

Reduced haemoglobin was infused through the venous catheter at time 0 . A dose of 500 $\mathrm{mg} / \mathrm{kg}$ in $1 \mathrm{ml}$ saline was administered as a bolus injection, followed by an infusion of the same amount over two minutes. To prevent acute changes in intravascular volume, an equal amount of blood from the arterial catheter was withdrawn. MAP was continuously recorded and pancreatic secretions collected in 10 minute fractions.

In separate studies, the effect of haemoglobin on pancreatic response to supramaximal caerulein was investigated. Haemoglobin was administered as described above. Two minutes after the end of haemoglobin infusion, caerulein $(10 \mu \mathrm{g} / \mathrm{kg})$ was administered and pancreatic juice collected for measurement of amylase output.

To exclude possible effects of an increase in oncotic pressure, albumin was infused in amounts that matched the oncotic capacity of haemoglobin..$^{35}$ Albumin $(485.5 \mathrm{mg} / \mathrm{kg})$ in $1 \mathrm{ml}$ saline was administered in the same way as haemoglobin, and MAP and amylase output measured.

The secretory pancreatic response was also examined after aminoguanidine treatment. Aminoguanidine ( $40 \mathrm{mg} / \mathrm{kg}$ body weight, i.v.) inhibits the inducible NOS isoform and was used as a control for inhibition of non-neural non-endothelial NOS.

\section{Induction of acute pancreatitis}

Acute pancreatitis was produced by administering a total of four i.p. injections of caerulein at the dose of $20 \mu \mathrm{g} / \mathrm{kg}$ body weight at one hour intervals in ketamine anaesthetised rats $(n=5$ per group). Indazole (50 mg/kg) was solubilised by sonication and warming in $4 \%$ ethanol in $0.5 \% \mathrm{Na}_{2} \mathrm{CO}_{3}, \mathrm{pH} 7.4$, and administered i.p. 30 minutes before induction of acute pancreatitis. To maintain adequate levels of indazole throughout the experiment, doses of $10 \mathrm{mg} / \mathrm{kg}$ indazole were administered i.m. at one hour intervals. Control rats received either vehicle alone or vehicle plus caerulein. Blood was obtained by cardiac puncture for determination of amylase activity nine hours after the first caerulein injection. Amylase activity was determined by the alpha amylase EPS test (Boehringer) for $\mathrm{BM} / \mathrm{Hitachi}$ system 717 . Aliquots of volume $200 \mu \mathrm{l}$ of $1: 800$ to $1: 2000$ dilutions of the sample were used in the assay.

To measure pancreatic oedema, excised pancreata were wet weighed, desiccated at $160^{\circ} \mathrm{C}$ for 24 hours and reweighed. Pancreatic 


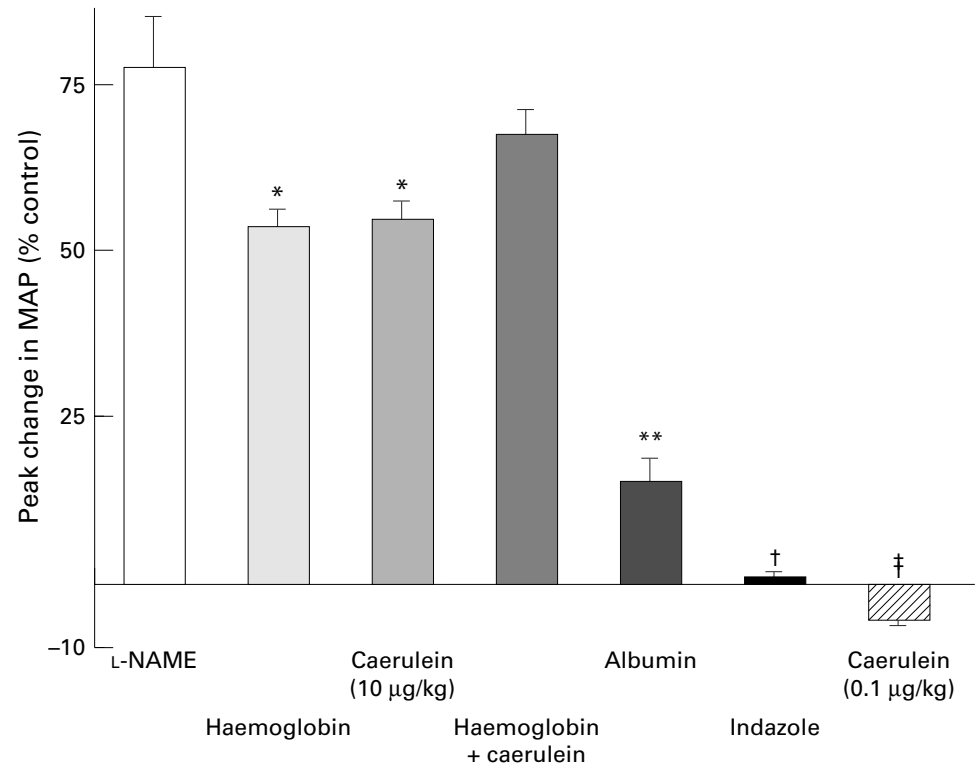

Figure 1 Effect of single doses of $L_{-}-N A M E$ (30 mg/kg, i.v.), haemoglobin (1 g/ $/ \mathrm{kg}, \mathrm{i} . v$.), supramaximal caerulein $(10 \mu \mathrm{g} / \mathrm{kg}, \mathrm{i}$.v.), haemoglobin plus supramaximal caerulein, albumin (970 mg/kg), indazole (100 mg/kg, i.p.), and suboptimal caerulein $(0.1 \mu \mathrm{g} / \mathrm{kg}$, $i$ v.) on mean arterial pressure $(M A P)$ in anaesthetised rats $(n=8$ for each experimental condition). Bars represent average percentage variation from control in peak MAP induced by drug administration. ${ }^{\star} p<0.05$ compared with $L-N A M E$ group. , and $\uparrow \neq p<0.05$ compared with all other groups.

water content was calculated as a percentage of total wet weight.

Tissue myeloperoxidase (MPO) activity was used as a biochemical marker for polymorphonuclear infiltration. It was determined using a previously described method ${ }^{36} 37$ that measures MPO activity as the result of $\mathrm{H}_{2} \mathrm{O}_{2}$ dependent oxidation of 3,3',5,5'-tetramethylbenzidine and expressed as units per mg protein.

\section{STATISTICAL ANALYSIS}

Results are presented as means (SEM). For statistical evaluations of differences between two groups of animals, Students's $t$ test for unpaired data was used. Differences between more than two groups of animals were

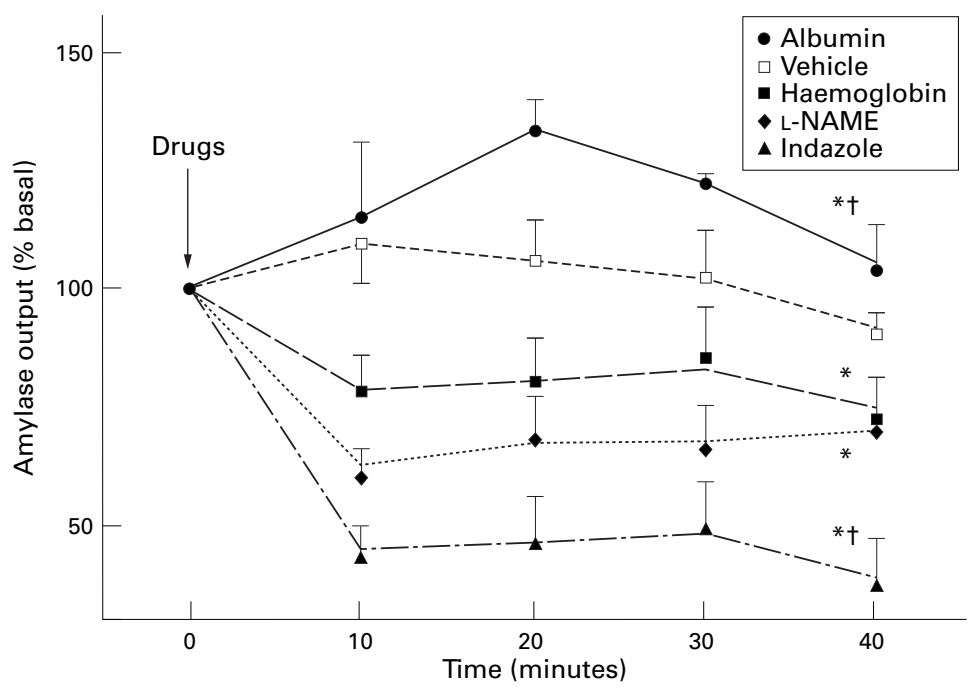

Figure 2 Time course of the effect of single bolus injections of $L-N A M E$, haemoglobin, albumin, indazole, or vehicle on amylase output expressed as percentage of variation from basal. Each point is the mean (SE) from five separate experiments for each experimental condition. Doses were as in fig $1 .{ }^{\star} p<0.05$ compared with vehicle. $t p<0.05$ compared with all groups. evaluated by analysis of variance. Statistical comparisons of data in fig 2 were performed using repeated measures analysis of variance followed by Fisher's protected least significant differences test. Differences were regarded as significant when $\mathrm{p}<0.05$.

\section{Results}

EFFECT OF NOS INHIBITORS, REDUCED HAEMOGLOBIN, AND CAERULEIN ON MAP

Basal MAP was 113 (2) $\mathrm{mm} \mathrm{Hg}$. Infusion of reduced haemoglobin produced a sharp and marked increase (fig 1 ). This effect was reversible, with MAP returning to baseline values in 11 (0.5) minutes. Supramaximal caerulein in $200 \mu \mathrm{l}$ saline also induced a sharp rise in MAP which matched that induced by haemoglobin, but with shorter duration (5.25 (0.4) minutes). In contrast, infusion of caerulein at submaximal doses of $0.1 \mu \mathrm{g} / \mathrm{kg}$ in the same amount of saline $(200 \mu \mathrm{l})$ induced a small but significant and transient (5 (0.7) minutes) reduction in MAP. The effect of i.v. bolus infusion of L-NAME was characterised by a progressive increase in MAP during the first 7.6 minutes, followed by a slow decline to 1.6 times baseline values by the end of the observation period. Peak change in MAP was greater after L-NAME infusion than after haemoglobin or caerulein infusion alone. Interestingly, the peak rise in MAP was enhanced by the combined treatment of supramaximal caerulein and haemoglobin, which then became similar to the peak change in MAP observed after L-NAME infusion.

Treatment with albumin in amounts that matched the expected oncotic capacity of haemoglobin raised MAP to a much lesser extent and duration (6.25 (0.25) minutes) than the response obtained by reduced haemoglobin or L-NAME. Indazole given either i.m. or i.p. showed no significant effects on MAP.

\section{EFFECT OF NOS INHIBITORS AND REDUCED}

HAEMOGLOBIN ON BASAL AMYLASE OUTPUT

As previously described, ${ }^{1}$ an i.v. L-NAME bolus of $30 \mathrm{mg} / \mathrm{kg}$ decreased basal amylase output (fig 2). Removal of circulating NO by infusion of reduced haemoglobin caused a decrease in amylase output of similar magnitude. In contrast, i.v. infusion of iso-oncotic amounts of albumin did not inhibit basal secretion. In fact, albumin produced a slight, but significant, increment in amylase output.

Systemic capsaicin treatment virtually abolished the eye wiping response to a local irritant, indicating effective defunctionalisation of sensory fibres. Inhibition of $\mathrm{nNOS}$ by indazole (fig 2) or capsaicin treatment (both systemically or locally applied) resulted in a reduction in basal amylase output. Capsaicin treatment reduced unstimulated amylase output relative to that of control rats $(47.4$ (8) $v 85.8$ (11) U/10 min; $\mathrm{p}<0.05)$, which was not statistically different from amylase output measured after indazole treatment (42.7 (7) U/10 $\mathrm{min}$ ).

Aminoguanidine, a non-neural nonendothelial inhibitor of NOS, had no detectable effect on basal amylase output $(n=5)$. 


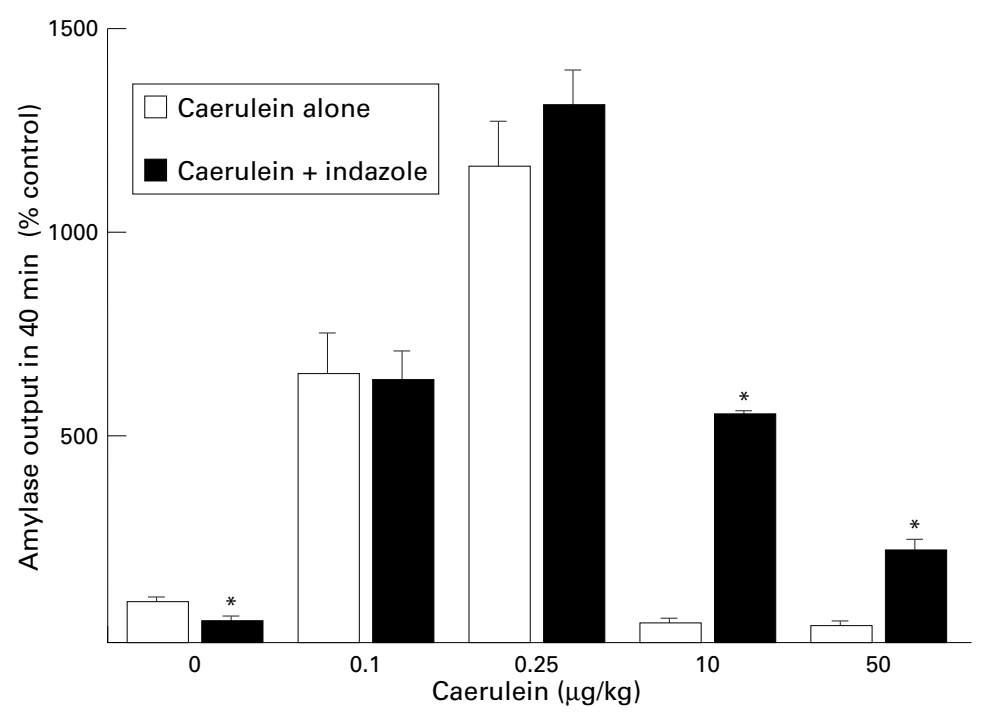

Figure 3 Amylase output in response to independent bolus doses of caerulein alone or caerulein plus indazole $(100 \mathrm{mg} / \mathrm{kg})$. Each bar represents percentage increment from baseline amylase output 40 minutes after caerulein infusion (means (SE)). Six or more separate experiments were conducted for each experimental condition. ${ }^{\star} p<0.05$ compared with caerulein alone.

EFFECT OF nNOS INHIBITION ON CAERULEIN STIMULATED PANCREATIC SECRETION Indazole did not modify amylase output in response to suboptimal and optimal doses of caerulein (fig 3). However, indazole treatment partially reversed the inhibitory effect of a supramaximal $(10 \mu \mathrm{g} / \mathrm{kg})$ dose of caerulein. Increasing the dose of caerulein to $50 \mu \mathrm{g} / \mathrm{kg}$ reduced the secretory response in indazole treated rats, suggesting that nNOS blockade induces a desensitisation of the inhibitory pathway activated by high doses of caerulein. No differences were observed in the amylase response to supramaximal caerulein, whether indazole was administered 2 or 50 minutes before caerulein (data not shown).

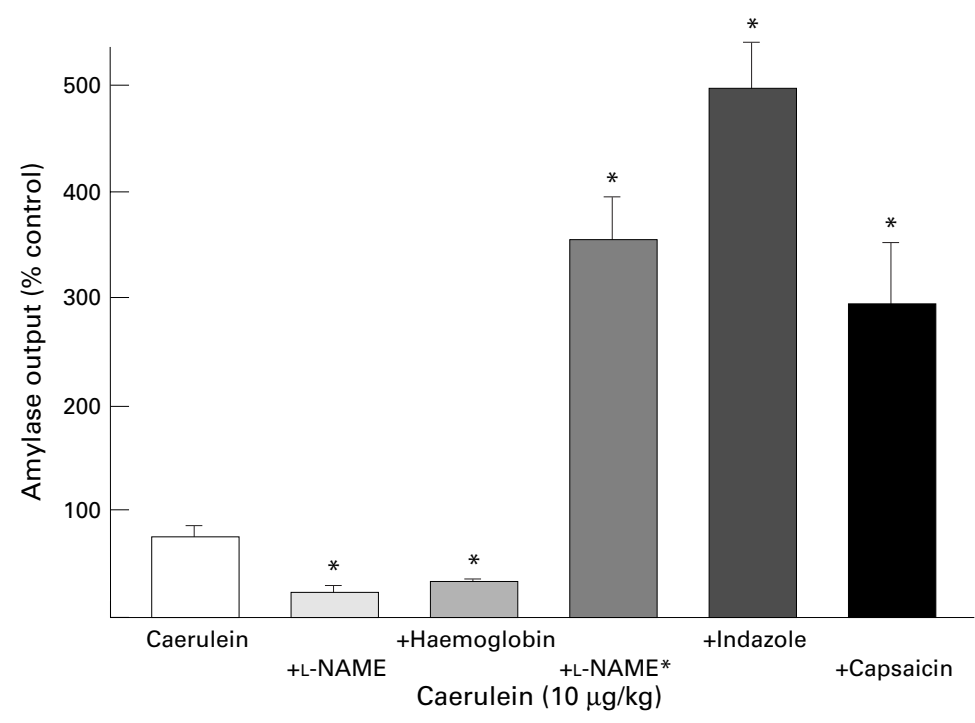

Figure 4 Amylase output in response to an intravenous bolus dose of caerulein $(10 \mu \mathrm{g} / \mathrm{kg})$. Caerulein was infused alone or after $L-N A M E(30 \mathrm{mg} / \mathrm{kg})$, haemoglobin $(1 \mathrm{~g} / \mathrm{kg})$, or indazole $(100 \mathrm{mg} / \mathrm{kg}$ ) administration or after afferent nerve ablation by local application of capsaicin. Drugs were given 2 minutes before caerulein except for $L-N A M E^{\star}$ ( 25 minutes) or capsaicin (five days before the experiments). Each bar represents percentage increment from baseline amylase output 40 minutes after caerulein infusion (means SE)). Six or more separate experiments were conducted for each experimental condition. ${ }^{*} p<0.05$ compared with caerulein alone.
Sensorial nerve ablation by capsaicin reproduced the effects of indazole treatment and rendered rats more sensitive to doses of caerulein that would ordinarily suppress amylase secretion (fig 4). This type of response was readily observed in all rats treated with capsaicin, whichever way capsaicin was administered, that is either via systemic or local application.

As expected, co-infusion of L-NAME and supramaximal caerulein induced a further reduction in amylase output as compared with caerulein alone. However, when nNOS was fully inhibited by L-NAME (administered 25 minutes before supramaximal caerulein) a paradoxical response occurred, since L-NAME counteracted the suppression of amylase output elicited by supramaximal caerulein alone (fig 4), in sharp contrast with the profound inhibition of amylase output observed when L-NAME was co-administered with caerulein.

EFFECT OF L-NAME AND REDUCED HAEMOGLOBIN ON PANCREATIC RESPONSE TO SUPRAMAXIMAL CAERULEIN

The decrease in circulating NO caused by reduced haemoglobin or L-NAME, when administered 2 minutes before supramaximal caerulein, potentiated the inhibition of amylase secretion produced by these doses of caerulein (fig 4). Thus removal of circulating $\mathrm{NO}$ is clearly detrimental to normal amylase secretion by the intact pancreas in vivo.

Inhibition of the inducible form of NOS by aminoguanidine did not modify the pancreatic response to supramaximal caerulein (260 (43) $\mathrm{U} / 40 \mathrm{~min}$ for caerulein alone $v 192$ (27) for caerulein plus aminoguanidine; $\mathrm{p}>0.05 ; \mathrm{n}=6$ ).

EFFECT OF nNOS INHIBITION ON CAERULEIN INDUCED ACUTE PANCREATITIS

Repeated i.p. caerulein $(20 \mu \mathrm{g} / \mathrm{kg}$ each) increased serum amylase $(32.2(3.6) \mathrm{U} / \mathrm{ml})$ and pancreatic water content $(81.3(0.9) \%$ of pancreatic weight) as compared with unstimulated rats $(4.3(0.4) \mathrm{U} / \mathrm{ml}$ and $71.2(1.3) \%$ respectively). Indazole treatment failed to either ameliorate or aggravate caerulein induced increments in these two parameters of early pancreatic injury $(28.2(2.6) \mathrm{U} / \mathrm{ml}$ and 82 $(1.1) \%)$. However, indazole reduced the increase in MPO activity induced by caerulein (1300 (148) $v 793$ (115) $\mathrm{mU} / \mathrm{mg}$ protein; $\mathrm{p}<0.05)$, indicating a putative permissive role for neural NO in polymorphonuclear infiltration to the pancreas.

\section{Discussion}

The issue investigated in our studies is which NOS isoform blocked by the non-specific inhibitor L-NAME is responsible for the observed inhibition of amylase output. To address this problem, we followed a pharmacological approach: pancreatic secretory pattern was measured in response to NOS antagonists.

To inhibit nNOS activity, indazole, a specific inhibitor, was employed. Indazole and certain related derivatives have been reported to selectively inhibit nNOS in vivo. ${ }^{16}{ }^{17}$ They show no effects on endothelial NOS and accordingly do not raise arterial blood pressure. ${ }^{19}{ }^{20}$ Certainly, 
indazole did not modify MAP in our experiments. However, impairment of nitrergic neurotransmission by nNOS inhibition reduced baseline amylase output. In the experimental design of the present work, biliopancreatic secretion is diverted from the duodenal lumen for 50 minutes before addition of drugs (stabilisation period plus two consecutive 10 minute periods to calculate "basal" secretion). Therefore basal secretion was most likely the result of endogenous cholecystokinin stimulation at picomolar (physiological) concentrations. $^{38}$ Our results on basal pancreatic secretion after indazole treatment are in close agreement with those obtained by $\mathrm{Li}$ et $a \mathrm{l}^{88}$ in response to biliopancreatic juice diversion after truncal vagotomy or perivagal application of capsaicin.

Although L-NAME inhibits all NOS isoenzymes, its effect on nNOS appears to be delayed with respect to endothelial NOS, since it is fully expressed after 15 minutes of systemic administration, ${ }^{11}$ whereas MAP (resulting from endothelial NOS inhibition) starts to increase in two to three minutes. This may explain why indazole had a greater impact on baseline amylase secretion, reflecting a regulatory function of nitrergic transmission in the maintenance of the neural pathways that control the normal physiology of baseline pancreatic secretion.

Indazole treatment showed no measurable effect on the secretory response to suboptimal and optimal doses of caerulein, but partially reversed the suppression of secretory activity elicited by supramaximal doses of caerulein, just as L-NAME when fully inhibiting nNOS. The pattern of response to indazole was reproduced by capsaicin. Basal secretion was reduced and supramaximal inhibition partially reversed. Both capsaicin application and nNOS inactivation result in an anti-nociceptive effect and prevention of neuropeptide release. ${ }^{112022-24}$ This suggests that impairment of neural NO transmission shifts the caerulein dose-response curve to the right, rendering anaesthetised rats less sensitive to cholecystokinin; they do not respond to low cholecystokinin concentrations (as induced by biliopancreatic juice diversion) but are capable of secretory responses to supramaximal doses of caerulein that would otherwise suppress amylase output.

We observed a dual effect of L-NAME on pancreatic secretion: when it is evaluated immediately after L-NAME infusion, inhibition of basal, optimal, and supramaximal caerulein stimulation occurs, as previously described. ${ }^{1}$ In contrast, when the pancreas is stimulated allowing a short lag period after L-NAME administration (25-35 minutes), the pattern of response parallels that observed after indazole or capsaicin treatment, two independent pharmacological approaches that impair sensorial nerve function. Subsequently, no further increases in arterial pressure are recorded (there is actually a slow decline in MAP) but L-NAME accomplishes full irreversible inhibition of nNOS. ${ }^{11}$ This suggests that nNOS inhibition may suppress or totally reverse the effects of endothelial NOS blockade on pancreatic secretion.
To obtain further support for this hypothesis we acutely removed NO from the intravascular bed by infusion of haemoglobin, an NO scavenger. Reduced haemoglobin avidly binds and inactivates $\mathrm{NO},{ }^{27}{ }^{39}$ but does not interfere with intracellular NO pathways or prevent neural NO transmission in vivo. ${ }^{26}$

An inhibitory effect of haemoglobin on NO mediated neurotransmission in vitro has been reported. ${ }^{40}$ However, our current understanding of the pharmacokinetics of native or artificially modified haemoglobins and their relation to NO binding argues against the conclusions drawn by some investigators on the effects of i.v. haemoglobin on NO neurotransmission in vivo. ${ }^{41}$ Owing to its high affinity for NO, intravenously infused haemoglobin rapidly reacts with circulating free $\mathrm{NO}$ (the reaction is essentially instantaneous) to form nitrate and methaemoglobin, which is the basis for a well known $\mathrm{NO}$ assay. ${ }^{42}$

Removal of free NO from the circulation induces a transient increase in MAP and an increase in peripheral vascular resistance. ${ }^{43} 44$ To scavenge NO close to any synaptic cleft in vivo, where NO might be released, haemoglobin should reach the extravascular space while still keeping its NO binding capacity. However, free circulating haemoglobin is likely to be rapidly processed into modified metabolites that may lose their NO affinity. In this regard, some haemoglobin derivatives even show vasodilator activity after having been nitrosylated. ${ }^{44}$ It is conceivable that some of the reported effects of haemoglobin on neurotransmission in vivo are related to effects caused by the activities of its catabolic products. $^{45} 46$

Under basal conditions, circulating NO mostly reflects endothelial NOS activity. NO is a major physiological regulator of basal systemic blood vessel tone. Continuous release of NO by vascular endothelial cells controls MAP in the resting state. ${ }^{47}$ Variations in MAP in response to NO inhibitors reflect, to a large extent, variations in the concentration of circulating free NO of endothelial origin. Indeed, haemoglobin infusion induced a sharp rise in MAP and a parallel reduction in amylase output. In contrast, iso-oncotic amounts of albumin resulted in a smaller increment in MAP while pancreatic secretion actually increased. The reason for this divergent effect may reside in the different interactions between both haemoglobin and albumin and free NO. Haemoglobin scavenges and inactivates $\mathrm{NO}^{27} 3944$ whereas albumin acts as a carrier for NO making it available to the microvasculature. ${ }^{48}$ Amylase output in response to supramaximal caerulein stimulation was further reduced when haemoglobin was given i.v., just as L-NAME does when it is co-administered with caerulein, and in sharp contrast with the pattern of secretion induced by indazole or capsaicin.

Interestingly, supramaximal caerulein induced an increase in MAP and potentiated the peak increase in MAP elicited by haemoglobin. Suboptimal doses of caerulein (which would induce plasma caerulein concentrations that 
match postprandial plasma cholecystokinin) did not increase MAP but, on the contrary, induced a transient reduction in MAP.

The effects of caerulein on the microvasculature have been known for a long time, but the mechanisms underlying this vasoreactivity are poorly understood. In dogs, i.v. bolus of caerulein at doses that effectively stimulate pancreatic secretion induce a fall in blood pressure. ${ }^{49}$ Likewise, the transient increase in MAP after $10 \mu \mathrm{g} / \mathrm{kg}$ caerulein is in agreement with reports of an increase in MAP after these doses of caerulein. ${ }^{50}$

It has been shown that NOS inhibition by L-NAME aggravates caerulein induced pancreatitis. ${ }^{129}$ Since indazole counteracted the suppression of amylase secretion in response to doses of caerulein that induce the development of pancreatitis, we examined whether or not indazole treatment could prevent pancreatic injury.

Moreover, NO has been involved in the pathogenesis of oedema formation in animal models of neurogenic inflammation. ${ }^{20}$ If neural NO contributes to oedema formation in caerulein induced pancreatitis, liquid accumulation in the pancreas would be expected to be prevented, at least in part, by indazole treatment.

In contrast with L-NAME effects when it is co-infused with caerulein, ${ }^{1}$ impairment of nitrergic transmission by indazole did not increase hyperamylasaemia in caerulein induced pancreatitis. Also, indazole had no measurable effect on liquid accumulation in the pancreas, suggesting that nitrergic transmission is not significantly involved in oedema formation in this model of inflammation. The fact that indazole reduced MPO activity is once again in opposition to the previously described effects of L-NAME in this situation, since L-NAME has been shown to increase MPO activity.

NOS is widely distributed in the body and may well be present in several cell types in a given organ, as in the case of the pancreas. General blockade of NOS by universal inhibitors such as L-NAME may give rise to contrasting effects in organ function, depending on the predominant pathway or cell function that is disrupted and on alternative activation of compensatory mechanisms. We should reconsider conclusions drawn from in vivo experiments, especially those in which L-NAME was given in repeated doses or for long periods of time. The use of inhibitors that selectively target different forms of NOS (best if cell selective) should be recommended, since they would produce more meaningful results.

We conclude that nitrergic nerve fibres play an important role in the control of pancreatic secretion, independently of other pancreatic NO sources. Pancreatic effects of nNOS inhibition differ from the effects resulting from endothelial NOS blockade, which we believe is the NO related event that produces inhibition of basal and stimulated secretion in vivo and the aggravation of acute pancreatitis.
1 Molero X, Guarner F, Salas A, et al. Nitric oxide modulates pancreatic basal secretion and response to cerulein in the rat: effects in acute pancreatitis. Gastroenterology $1995 ; 108: 1855-62$.

2 Holst JJ, Rasmussen TN, Schmidt P. Role of nitric oxide in neurally induced pancreatic exocrine secretion in pigs. $\mathrm{Am}$ f Physiol 1994;266:G206-13.

3 Patel AG, Toyama MT, Nguyen TN, et al. Role of nitric oxide in the relationship of pancreatic blood flow and exocrine secretion in cats. Gastroenterology 1995;108:1215-20.

4 Konturek SJ, Bilski J, Konturek PK, et al. Role of endogenous nitric oxide in the control of canine pancreatic secretion and blood flow. Gastroenterology 1993;104:896902 .

5 Shimosegawa T, Abe T, Satoh A, et al. Histochemical demonstration of NADPH-diaphorase activity, a marker for nitric oxide synthase, in neurons of the rat pancreas. Neurosci Lett 1992;148:67-70.

6 Schmidt HH, Warner TD, Ishii K, et al. Insulin secretion from pancreatic $\beta$ cells caused by L-arginine-derived nitrogen oxides. Science 1992;225:721-3.

7 Schmidt HHHW, Gagne GD, Nakane M, et al. Mapping of neural nitric oxide synthase in the rat suggests frequent co-localization with NADPH diaphorase but not with soluble guanylyl cyclase, and novel paraneural functions of nitrergic signal transduction. F Histochem Cytochem 1992; 40:1439-56.

8 Gukovskaya AS, Pandol SJ. Nitric oxide production regulates cGMP formation and calcium influx in pancreatic acinar cells. Am 7 Physiol 1994;266:G350-6.

9 Menozzi D, Sato T, Jensen RT, et al. Cyclic GMP does not inhibit protein kinase C-mediated enzyme secretion in rat pancreatic acini. $\mathcal{F}$ Biol Chem 1989;264:995-9.

10 Gardiner SM, Compton AM, Kemp PA, et al. Regional and cardiac hemodynamic effects of $\mathrm{N}^{\mathrm{G}}$-nitro-L-arginine methyl ester in conscious, Long Evans rats. $\mathrm{Br} \mathcal{F}$ Pharmacol 1990;101:625-31.

11 Moore PK, Oluyomi AO, Babbedge RC, et al. L-N ${ }^{\mathrm{G}}$-nitro arginine methyl ester exhibits antinociceptive activity in the mouse. Br f Pharmacol 1991;102:198-202.

12 Salehi A, Carlberg M, Henningson R, et al. Islet constitutive nitric oxide synthase: biochemical determination and regulatory function. Am f Physiol 1996;270:C1634-41.

13 Southan GJ, Szabó C. Selective pharmacological inhibition of distinct nitric oxide synthase isoforms. Biochem Pharmacol 1996;51:383-94.

14 Dwyer MA, Bredt DS, Snyder SH. Nitric oxide synthase: irreversible inhibition by $\mathrm{L}-\mathrm{N}^{\mathrm{G}}$-nitroarginine in brain in vitro and in vivo. Biochem Biophys Res Commun 1991;176: $1136-41$.

15 Furfine ES, Harmon MF, Paith JE, et al. Selective inhibition of constitutive nitrergic oxide synthase by $\mathrm{L}^{-\mathrm{N}^{\mathrm{G}}}$ of constitutive nitrergic oxide synthase

16 Babbedge RC, Bland-Ward PA, Moore Pk. Inhibition of rat cerebellar nitric oxide syntase by 7 -nitro indazole and cerebellar nitric oxide syntase by 7 -nitro indazole and
related substituted indazoles. Br 7 Pharmacol 1993;110: related $25-8$.

17 Moore PK, Wallace P, Gaffen Z, et al. Characterization of the novel nitric oxide synthase inhibitor 7-nitro indazole and related indazoles: antinocioceptives and cardiovascular effects. Br 7 Pharmacol 1993;110:219-24.

18 Faraci FM, Brian JE. 7-nitroindazole inhibits brain nitric oxide synthase and cerebral vasodilatation in response to N-methyl-D-aspartate. Stroke 1995;26:2172-6.

19 Moore PK, Wallace P, Gaffen Z, et al. 7-nitroindazole, an inhibitor of nitric oxide synthase, exhibits antinocioceptive activity in the mouse without increasing blood presure. $\mathrm{Br}$ F Pharmacol 1993;108:296-7.

20 Kajekar R, Moore PK, Brain SD. Essential role for nitric oxide in neurogenic inflammation in rat cutaneous oxide in neurogenic inflammation in
microcirculation. Circ Res 1995;76:441-7.

21 Buck SH, Burks TF. The neuropharmacology of capsaicin: a review of some recent observations. Pharmacol Rev 1986; 38:179-226

22 Bevan S, Szolcsnyi J. Sensory neuron-specific actions of capsaicin: mechanisms and applications. Trends Pharmacol Sci 1990;11:330-3.

23 Dray A. Mechanism of action of capsaicin-like molecules on sensory neurons. Life Sci 1992;51:1759-65.

24 Birder LA, Kanai AJ, Groat WC. DMSO: effect on bladder afferent neurons and nitric oxide release. F Urol 1997;158: 1989-95.

25 Ren K, Ruda MA. Nitric oxide synthase-containing neurons in sensory ganglia of the rat are susceptible to capsaicinin sensory ganglia of the rat are susceptible to cap

26 Jenkinson KM, Reid JJ, Rand MJ. Hydroxocobalamin and haemoglobin differentiate between exogenous and neuronal nitric oxide in the rat gastric fundus. Eur 7 Pharmacol $1995 ; 275: 145-52$

27 Feelish M, Noack EA. Correlation between nitric oxide formation during degradation of organic nitrates and activation of guanylate cyclase. Eur $\mathcal{F}$ Pharmacol 1987;139: 19-30.

28 Salvemini D, Radziszewski W, Karbut R, et al. The use of oxyhaemoglobin to explore the events underlying inhibition of platelet aggregation induced by $\mathrm{NO}$ or NO-donors. Br F Pharmacol 1990;101:991-5.

29 Werner J, Rivera J, Fernandez-del Castillo C, et al. Differing roles of nitric oxide in the pathogenesis of acute edematous versus necrotizing pancreatitis. Surgery 1997;121:23-30.

30 Dale WE, Turkelson CM, Solomon TE. Role of cholecystokinin in intestinal phase of meal-induced pancreatic secretion. Am f Physiol 1989;257:G782-90. 
31 Maouyo D, Guan D, Rivard N, et al. Stability of circadian and minor cycles of exocrine pancreatic secretion in 268:G251-9.

32 Martling CR. Sensory nerves containing tachykinins and cGRP in the lower airways. Acta Physiol Scand Suppl 1987; 563:1-57.

33 Girolomoni G, Tigelaar RE. Capsaicin-sensitive primary sensory neurons are potent modulators of murine delayedtype hypersensitive reactions. F Immunol 1990;145:110512 .

34 Martin W, Villani GM, Jothianandan D, et al. Selective trinitrate-induced relaxation by hemoglobin and by methylene blue in the rabbit aorta. F Pharmacol Exp Ther 1985; 232:708-16.

35 Thompson A, McGarry AE, Valeri CR, et al. Stroma-free hemoglobin increases blood pressure and GRF in the hypotensive rat: role of nitric oxide. $\mathcal{F}$ Appl Physiol 1994;77: hypotensive 24.

36 Grisham MB, Benoit JN, Granger DN. Assessment of leukocyte involvement during ischemia and reperfusion of the intestine. Methods Enzymol 1990;186:729-41.

37 Yamada T, Sartor RB, Marshall S, et al. Mucosal injury and inflammation in a model of chronic granulomatous colitis in rats. Gastroenterology 1993;104:759-71.

$38 \mathrm{Li} \mathrm{Y}$, Owyang C. Endogenous cholecystokinin stimulates pancreatic enzyme secretion via vagal afferent pathway in rats. Gastroenterology 1994;107:525-31.

39 Moncada S, Palmer RMJ, Higgs EA. Nitric oxide: physiology, pathophysiology, and pharmacology. Pharmacol Rev 1991;43:109-42.
40 Rattan S, Rosenthal GJ, Chakder S. Human recombinant hemoglobin ( $\mathrm{rHb} 1.1)$ inhibits nonadrenergic noncholinergic (NANC) nerve-mediated relaxation of internal anal sphincter. F Pharmacol Exp Ther 1995;272:1211-16.

41 Murray JA, Ledlow A, Launspach J, et al. The effects of recombinant human hemoglobin on esophageal motor function in humans. Gastroenterology 1995;109:1241-8.

42 Hevel JM, Marletta MA. Nitric-oxide synthase assays. Methods Enzymol 1994;233:250-8.

43 Hess JR, MacDonald VW, Brinkley WW. Systemic and pulmonary hypertension after resucitation with cell-free monary hypertension after resucitation with
hemoglobin. f Appl Physiol 1993;74:1769-78.

44 Jia L, Bonaventura C, Bonaventura J, et al. S-nitrosohaemoglobin: a dynamic activity of blood involved in vascular control. Nature 1996;380:221-6.

45 Somers M, Piqueras AI, Strange K, et al. Interactions of ultrapure bovine hemoglobin with renal epithelial cells in vivo and in vitro. Am F Physiol 1997;273:F38-52.

46 Everse J, Hsia N. The toxicities of native and modified hemoglobins. Free Radic Biol Med 1997;22:1075-99.

47 Rees DD, Palmer RMJ, Moncada S. Role of endotheliumderived nitric oxide in the regulation of blood pressure. Proc Natl Acad Sci USA 1989;86:3375-8.

48 Stamler JS, Jaraki O, Osborne JA. Nitric oxide circulates in mammalian plasma primarily as an S-nitroso adduct of serum albumin. Proc Natl Acad Sci USA 1992;89:7674-7.

49 Erspamer V, Bertaccini G, De Caro G, et al. Pharmacological actions of caerulein. Experientia 1967;23:702-3.

50 Bertolini A, Guarini S, Ferrari W, et al. Caerulein and cholecystokinin reverse experimental hemorrhagic shock. Neuropeptides 1986;8:25-31. 